\title{
A Case of Esophageal Intramural Pseudodiverticulosis
}

\author{
Young Eun Chon*, Sena Hwang*, Kyu Sik Jung*, Hyun Jung Lee*, Sang Gil Lee*, ${ }^{\dagger}$, Sung Kwan Shin*, ${ }^{\dagger}$, and Yong Chan \\ Lee*,† $^{*,}$ \\ *Department of Internal Medicine and ${ }^{\dagger}$ Institute of Gastroenterology, Yonsei University College of Medicine, Seoul, Korea
}

Esophageal intramural pseudodiverticulosis (EIP) is a rare benign disease that is characterized by multiple tiny flaskshaped outpouching lesions of the esophageal wall. The etiology is unknown, but the pathologic findings include dilatation of excretory ducts of submucosal glands. The predominant symptom is dysphagia, and esophageal stricture occurs frequently. Diseases such as diabetes mellitus, esophageal candidiasis, gastroesophageal reflux disease, and chronic alcoholism are often combined. Since most EIP cases are benign, the mainstream treatment is symptom relief by endoscopic dilatation or medical treatment of accompanied diseases. This report describes the case of a 68-year-old male patient who suffered from chest tightness for 2 months and was diagnosed with EIP. This symptom disappeared after 2 months of medical treatment, and the patient is now being regularly followed up. (Gut Liver 2011;5:93-95)

Key Words: Esophageal intramural pseudodiverticulosis; Esophageal neoplasms

\section{INTRODUCTION}

Esophageal intramural pseudodiverticulosis (EIP) is a rare benign disease manifested by multiple small flask-shaped outpouchings protruding from the esophageal lumen to the wall. About 200 cases of EIP have been reported world-wide. ${ }^{1}$ EIP is diagnosed by characteristic findings on esophagography or esophago-gastro-duodenoscopy (EGD) and pathologic findings reveal abnormal dilatation of the submucosal glands. The predominant symptom is dysphagia often accompanied by an esophageal stricture. Here, we report a patient who suffered from chest tightness for two months, and was diagnosed as EIP by esophagography and EGD. The symptom was relieved only by taking medicine for two months, but pseudodiverticula did not vanish.

\section{CASE REPORT}

A 68-year-old male presented with chest tightness for two months. He had no symptoms of dysphagia, odynophagia, nausea, vomiting, or weight loss. He had a medical history of diabetes mellitus and hypertension. He was a heavy smoker with a history of 1,000 packs per year and a heavy drinker who drank everyday for 50 years. He had a chronic ill-looking appearance, but had an alert mental status. He had no family history of diseases. At first, we suspected him to have ischemic heart disease, and performed electrocardiogram (EKG), cardiac enzyme, and treadmill tests. As these tests revealed normal results, we suspected him to have gastrointestinal disease. On EGD, innumerable tiny openings of pseudodiverticula with scattered yellowish follicles around them were noted through the entire esophagus (Fig. 1). An esophageal stricture was not present. Biopsy performed after spraying the lugol solution revealed chronic super-

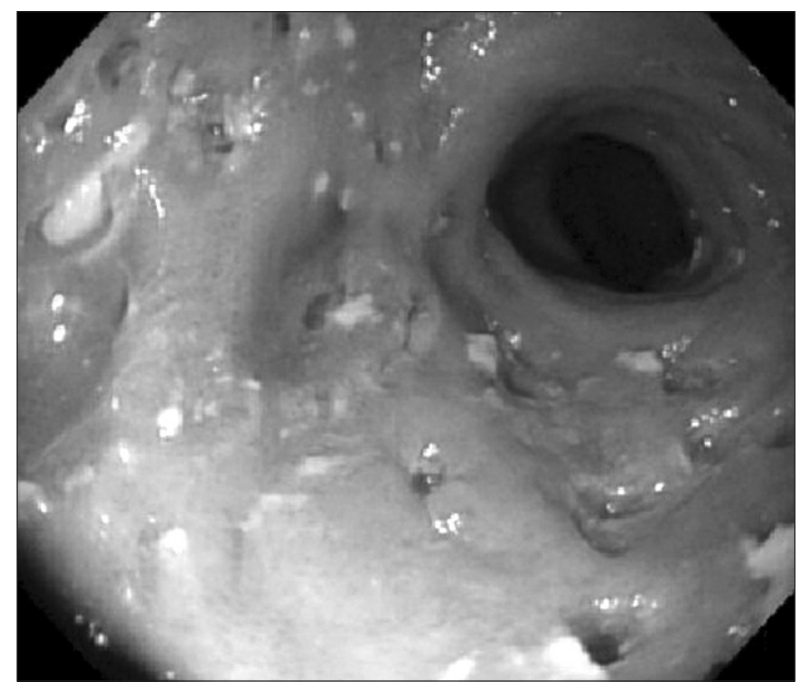

Fig. 1. Upper gastrointestinal endoscopic findings showing many tiny pseudodiverticular openings, whitish scar lesions, and yellowish follicles in the entire esophagus.

\footnotetext{
Correspondence to: Yong Chan Lee

Department of Internal Medicine, Yonsei University College of Medicine, 250 Seongsanno, Seodaemun-gu, Seoul 120-752, Korea

Tel: +82-2-2228-1960, Fax: +82-2-393-6884, E-mail: leeyc@yuhs.ac

Received on December 30, 2009. Accepted on March 20, 2010.

pISSN 1976-2283 eISSN 2005-1212 DOI: 10.5009/gnl.2011.5.1.93
} 


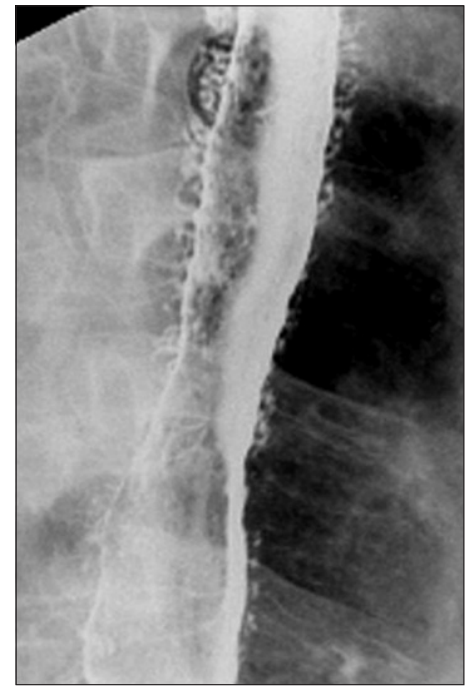

Fig. 2. Barium esophagography reveals multiple flask-shaped outpouchings in the esophageal wall.

ficial inflammation. A barium esophagogram disclosed mucosal irregularities from the upper esophagus up to the esophago-gastric junction with outpouchings in many breaking points (Fig. 2). After using a proton pump inhibitor (PPI) for two months, chest tightness disappeared. Six months later, an EGD was performed again for the follow up. Scattered innumerable tiny outpouchings in the entire esophagus showed no difference from the last EGD findings. The patient is being followed for two years at the outpatient clinic.

\section{DISCUSSION}

Since Mendl et al. ${ }^{2}$ first reported EIP in 1960, about 200 EIP reports have been published world-wide. ${ }^{1}$ In one report where an esophagogram was performed in over 14,350 patients, EIP was found in $21(0.15 \%)$ patients. ${ }^{3}$ Still, the pathogenesis of EIP is not exactly known. Histologically, pathologically dilated submucosal glands and excretory ducts were detected. ${ }^{4-7}$ Considering the presence of inflammatory cells around excretory ducts, it has been suggested that the ducts were obstructed by inflammation of epithelial cells or mucus around the ducts. ${ }^{4,5}$ On the contrary, others asserted submucosal fibrosis caused by chronic irritation had resulted in the obstruction of the ductal orifices. ${ }^{8}$

EIP shows bimodal peak incidence in teens ${ }^{9,10}$ and in the fifties and sixties. ${ }^{11,12}$ Patients who have a coexisting disease such as diabetes mellitus, esophageal candidiasis, reflux esophagitis, chronic alcohol abuse, and corrosive acid injury have a higher risk to develop EIP., ${ }^{8,13}$ EIP is often associated with benign esophageal disease, but there are several reports where EIP was associated with esophageal cancer. ${ }^{3,14}$ In one report, a 60-yearold male patient had esophageal cancer in the cervical esophagus and EIP throughout the whole esophagus. After radiation treatment for the esophageal cancer, the primary site of esopha- geal cancer was improved and EIP almost disappeared. ${ }^{15}$ In one report, EIP was developed in 4.5\% of patients with esophageal cancer and in $0.09 \%$ of patients without esophageal cancer. Moreover, the difference between the prevalence of EIP in patients with carcinoma and that in patients without carcinoma was statistically significant $(\mathrm{p}<0.0002) .{ }^{14}$ Hence, when esophageal stricture is present in EIP, esophageal cancer should be suspected and relevant tests should be warranted.

EIP appears as multiple small flask-shaped outpouchings measuring about 1-4 mm in length and 1-2 mm in width., The number of pseudodiverticula varies from less than five to over 20. EIPs are distributed diffusely in $60 \%$ of patients and segmentally in 40\% (upper 14\%, middle 14\%, and lower 12\%) of patients. ${ }^{8,11}$ In our case, pseudodiverticula were diffusely present through the entire esophagus. An esophageal stricture is observed in 76-90\% of patients, which are most common in the upper esophagus, followed by the lower esophagus and middle esophagus. ${ }^{8,12}$ In our patient, an esophageal stricture was found neither at first nor on the follow up EGD performed six months later. In 25\% of patients, the openings of the EIP are found on the endoscopy. In some cases, yellowish exudative secretion was noted at the openings, and the mucosal layers around the openings were elevated. ${ }^{8,11}$ Although endoscopic biopsies revealed acute or chronic inflammation in many cases, the diagnoses were often indecisive because pseudodiverticula were intramural and not included in the biopsy specimen. ${ }^{8}$ In our case, numerous small follicles were noted around the pseudodiverticula, and yellowish exudations were drained from the openings by pressing them using forceps. The biopsy results indicated chronic superficial inflammation. On computed tomography, the esophageal wall was hypertrophied and the lumen was irregularly narrowed. ${ }^{8}$ Manometry shows various patterns of esophageal motility from normal to localized aperistalsis confined to the area of esophageal narrowing, diffuse aperistalsis of the esophagus, decreased amplitude with normal peristalsis, decreased amplitude with aperistalsis, primary diffuse esophageal spasm, high amplitude peristaltic contraction, and normal amplitude synchronous tertiary contractions. ${ }^{16}$

The most common symptom observed in over $80 \%$ of patients is intermittent or progressive dysphagia, from which patients suffer for several months to several years before the diagnosis. Our patient did not have dysphagia, but suffered from chest tightness for two months. On the other hand, some patients experience odynophagia while others have no symptoms and are incidentally diagnosed with EIP by endoscopy.

The treatment for EIP is directed towards treating accompanied diseases and relieving symptoms. ${ }^{11,12}$ About 10\% of patients require no treatment. ${ }^{17}$ If there is concomitant reflux esophagitis or candidiasis, conservative treatment for these diseases sometimes improved both the symptoms and the pseudodiverticulosis. ${ }^{16}$ However, when there is an accompanied esophageal stricture, mechanical endoscopic dilatation 
leads to clinical treatment response. ${ }^{11}$ Cho et al. ${ }^{12}$ reported that symptoms were markedly improved by dilating the esophageal stricture accompanied by pseudodiverticulosis. Moreover, by dilating the esophageal stricture, pseudodiverticula was reduced or disappeared in some selected cases. ${ }^{13,18}$ Our case was unique in that selected chest tightness disappeared after treating only the reflux symptom while pseudodiverticula remained during the follow up period. Esophagitis has been known to be associated with EIP in about $9 \%$ of patients, ${ }^{19}$ and it is also associated with hypertensive lower esophageal sphincter. ${ }^{20,21}$ Thus, Bender et al. ${ }^{16}$ presumed that diverticular formation might have been mediated by motility changes secondary to esophagitis. Applying this theory to our patient, chest tightness could have disappeared because esophagitis was effectively treated by inhibiting acid secretion with PPI. However, it might have been too progressed to recover esophageal herniation of the mucosa which has gone through irreversible change.

In conclusion, we report a case of an EIP patient whose reflux symptom was relieved by only medical treatment, but pseudodiverticula, did not show improvement for two years of the follow up period.

\section{REFERENCES}

1. Hahne M, Schilling D, Arnold JC, Riemann JF. Esophageal intramural pseudodiverticulosis: review of symptoms including upper gastrointestinal bleeding. J Clin Gastroenterol 2001;33:378-382.

2. Mendl $\mathrm{K}$, Tanner $\mathrm{CH}$. Intramural diverticulosis of the oesophagus and Rokitansky-Aschoff sinuses in the gall-bladder. Br J Radiol 1960;33:496-501.

3. Levine MS, Moolten DN, Herlinger H, Laufer I. Esophageal intramural pseudodiverticulosis: a reevaluation. AJR Am J Roentgenol 1986;147:1165-1170.

4. Wightman AJ, Wright EA. Intramural oesophageal diverticulosis: a correlation of radiological and pathological findings. Br J Radiol 1974;47:496-498.

5. Umlas J, Sakhuja R. The pathology of esophageal intramural pseudodiverticulosis. Am J Clin Pathol 1976;65:314-320.

6. Rahlf G, Wilbert L, Lankisch PG, Huttemann U. Intramural esophageal diverticulosis. Acta Hepatogastroenterol (Stuttg) 1977;24:110115.

7. Fromkes J, Thomas FB, Mekhjian H, Caldwell JH, Johnson
JC. Esophageal intramural pseudodiverticulosis. Am J Dig Dis 1977;22:690-700.

8. Sabanathan S, Salama FD, Morgan WE. Oesophageal intramural pseudodiverticulosis. Thorax 1985;40:849-857.

9. Peters ME, Crummy AB, Wojtowycz MM, Toussaint JB. Intramural esophageal pseudodiverticulosis: a report in a child with a 16-year follow up. Pediatr Radiol 1983;13:229-230.

10. Weller MH. Intramural diverticulosis of the esophagus: report of a case in a child. J Pediatr 1972;80:281-285.

11. Bruhlmann WF, Zollikofer CL, Maranta E, et al. Intramural pseudodiverticulosis of the esophagus: report of seven cases and literature review. Gastrointest Radiol 1981;6:199-208.

12. Cho SR, Sanders MM, Turner MA, Liu CI, Kipreos BE. Esophageal intramural pseudodiverticulosis. Gastrointest Radiol 1981;6:9-16.

13. Kochhar R, Mehta SK, Nagi B, Goenka MK. Corrosive acidinduced esophageal intramural pseudodiverticulosis. A study of 14 patients. J Clin Gastroenterol 1991;13:371-375.

14. Plavsic BM, Chen MY, Gelfand DW, et al. Intramural pseudodiverticulosis of the esophagus detected on barium esophagograms: increased prevalence in patients with esophageal carcinoma. AJR Am J Roentgenol 1995;165:1381-1385.

15. Naoi Y, Katayama H, Tomiyoshi H. Esophageal intramural pseudodiverticulosis with esophageal cancer improved by target rotation irradiation: case report. Nippon Igaku Hoshasen Gakkai Zasshi 1997;57:526-527.

16. Bender MD, Haddad JK. Disappearance of multiple esophageal diverticula following treatment of esophagitis: serial endoscopic, manometric, and radiologic observations. Gastrointest Endosc 1973;20:19-22.

17. Stephens WP, Mossman A, Ratcliffe JF, Gould DA, Oleesky S. Intramural pseudodiverticulosis--an unusual cause of benign oesophageal stricture. Postgrad Med J 1986;62:201-204.

18. Ramakantan R, Shah P. Intramural pseudodiverticulosis of the esophagus in corrosive strictures: report of three cases. Can Assoc Radiol J 1990;41:90-92.

19. Allen TH, Clagett OT. Changing concepts in the surgical treatment of pulsion diverticula of the lower esophagus. J Thorac Cardiovasc Surg 1965;50:455-462.

20. Cross FS. Esophageal diverticula related neuromuscular problems. Ann Otol Rhinol Laryngol 1968;77:914-926.

21. Olsen AM, Schlegel JF. Motility disturbances caused by esophagitis. J Thorac Cardiovasc Surg 1965;50:607-612. 